\title{
Stimmungsbilder von der Langen Nacht der Museen am 14. März 2015
}

Zum vorerst letzten Mal beteiligte sich die Württembergische Landesbibliothek an der Langen Nacht der Museen, bevor - baubedingt - eine mehrjährige Unterbrechung folgt. Die rund 1.450 Besucherinnen und Besucher nutzten noch einmal die Gelegenheit, das abwechslungsreiche Programm zu erleben. Betina Ignacio (offizieller Künstlername Bê Ignacio), die bereits das dritte Mal zu Gast bei der Langen Nacht in der WLB war, entführte das Publikum auf eine musikalische Reise nach Brasilien und begeisterte alle mit einem stimmungsvollen Mix aus bekannten und aktuellen Songs einschließlich ihres erfolgreichen

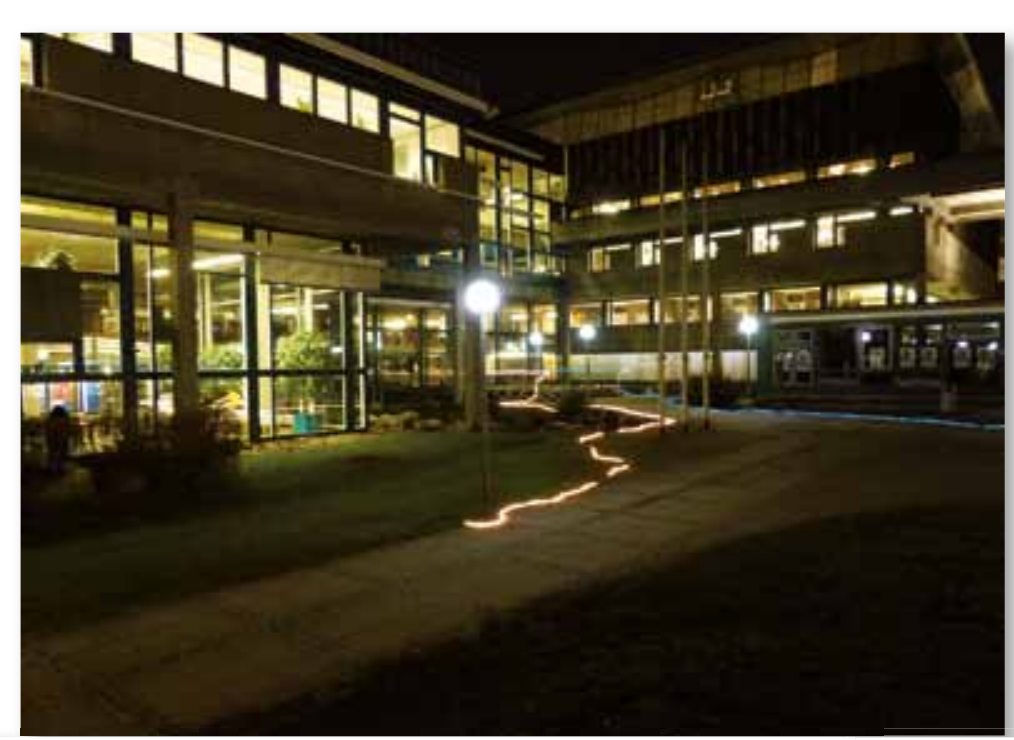

Albums "Indiana Urbana" (=Großstadtindianerin). Wieder einmal zog sie das Publikum mit ihrer ausdrucksstarken und sinnlichen Stimme in den Bann. Keinesfalls fehlen durften die altbewährten und beliebten Führungen durch das Magazin und die Digitalisierungswerkstatt. An der Grenze zwischen Realität und Phantasie fanden sich die Zuhörer im mitternächtlichen Lesesaal - eine perfekte Kulisse für die von Ute Oelmann exzellent vorgetragene Kurzgeschichte "Gespenster" von Marie Louise Kaschnitz, deren traumhafte, unheimliche Handlung sich ideal in die dunklen Schatten des Lesesaals einfügte. Die Ausstellung "Carl Eugens Erbe" erinnerte an das große, kürzlich gefeierte 250-jährige Jubiläum und spiegelte die Vielseitigkeit und Lebendigkeit der historischen und aktuellen Bibliothek wider. Die elfte Teilnahme an der Langen Nacht der Museen war wieder sehr lohnenswert. Gespannt darf man schon jetzt auf eine zukünftige Veranstaltung im Erweiterungsbau sein, die sicherlich neue atmosphärische Reize entfalten dürfte.

Jörg Ennen

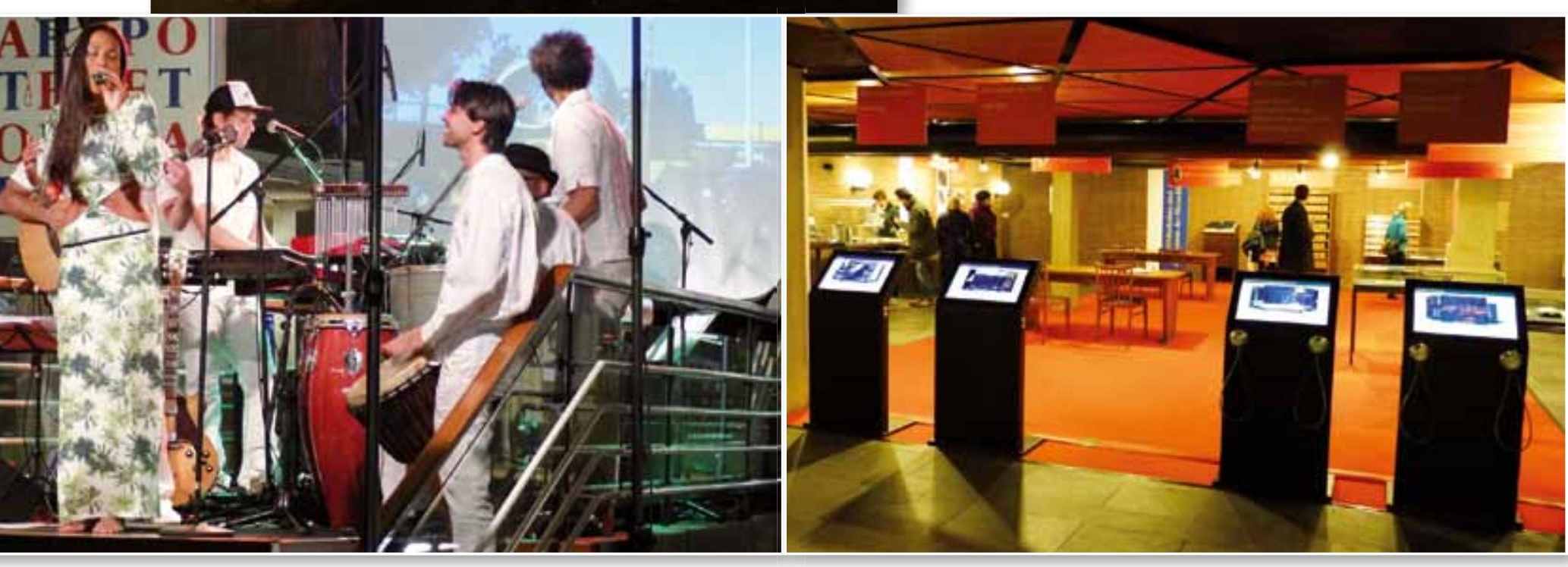




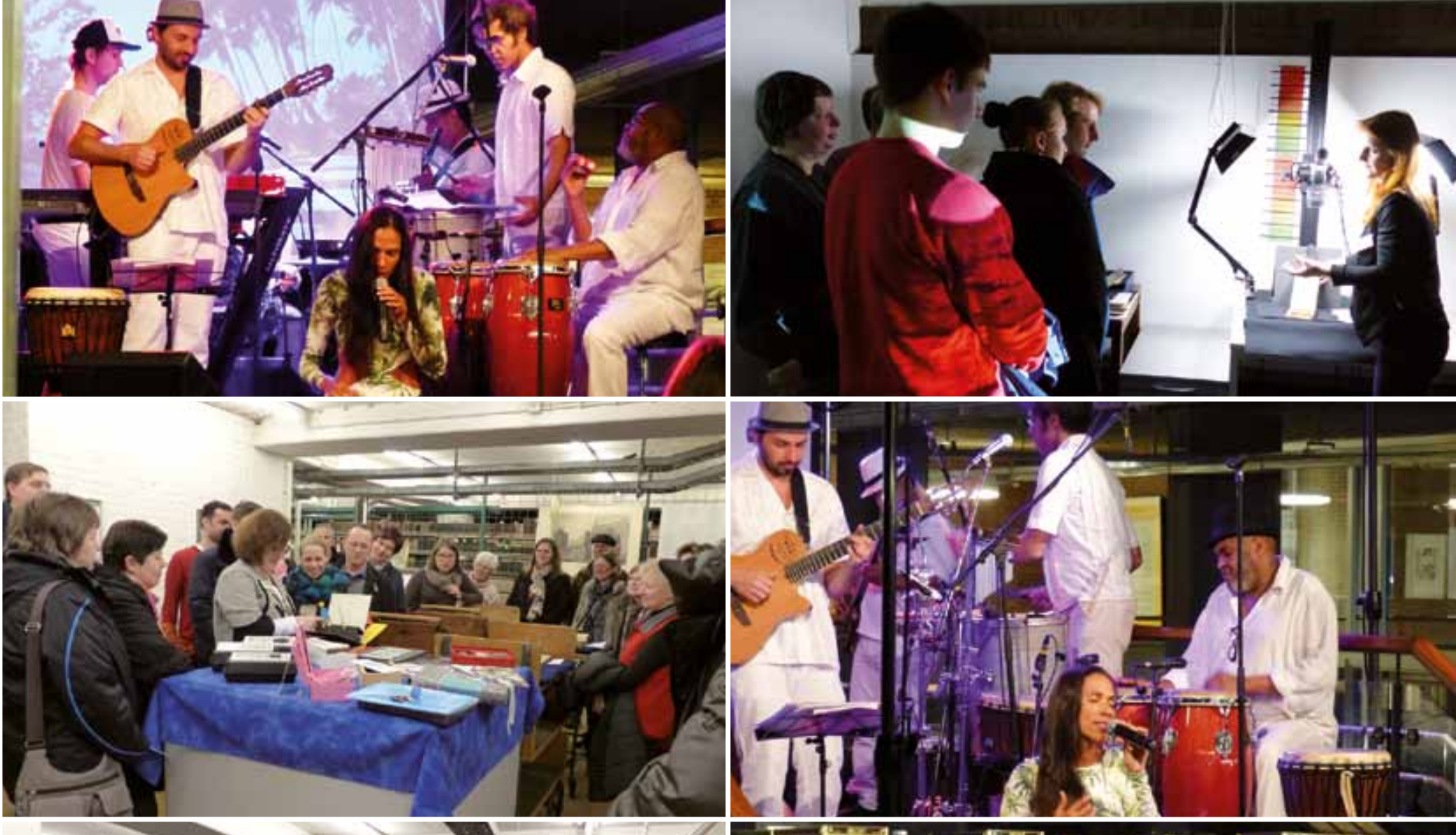

निता ये

4. 2u

i)

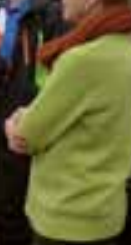

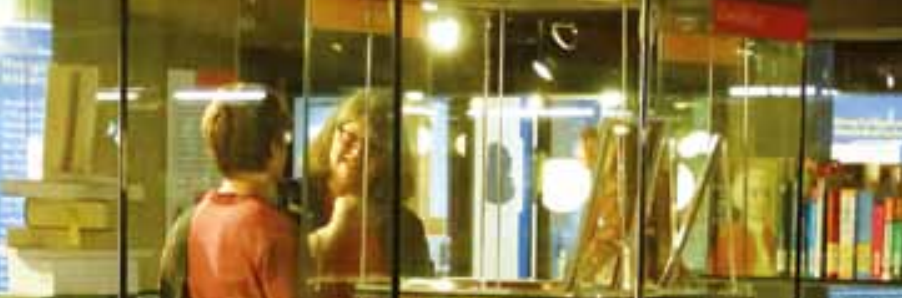

$-4$ 